\title{
Enunciados que Constituem as Docências em Matemática nos Anos Iniciais do Ensino Fundamental
}

\author{
Statements that Constitute Mathematics Teaching in the Initial \\ Years of Elementary Education
}

\author{
Fernanda Wanderer* \\ ORCID iD 0000-0002-8198-7104 \\ Fernanda Longo** \\ ORCID iD 0000-0002-0925-1303
}

\begin{abstract}
Resumo
O artigo problematiza enunciados que conformam o discurso da Educação Matemática e seus efeitos de verdade sobre as práticas pedagógicas das professoras que atuam nos Anos Iniciais do Ensino Fundamental. Os aportes teóricos que sustentaram a investigação são as teorizações de Michel Foucault, em especial os conceitos de discurso e enunciado. O material de pesquisa é composto por entrevistas com docentes que lecionam em turmas do $3^{\circ}$ ou $4^{\circ}$ Anos na rede privada de ensino de Porto Alegre. A estratégia analítica utilizada para examinar o material orientou-se pela análise do discurso na perspectiva de Michel Foucault. O exame do material evidenciou a presença de dois enunciados constituindo o discurso da Educação Matemática nos Anos Iniciais: "a importância do uso do material concreto e dos recursos digitais nas aulas de Matemática" e "a relevância do registro e da formalização do conhecimento matemático como garantia da aprendizagem". Assim, pode-se concluir, com base nas entrevistas realizadas, que as docências em matemática nos Anos Iniciais estão sustentadas por enunciados que fazem parte de diferentes campos discursivos, mas que predominam aqueles pautados no construtivismo e nos ideais platônicos, conduzindo os processos pedagógicos em uma forma ascendente: dos usos dos materiais concretos para a sistematização e formalização, tornando esta etapa final como a mais relevante e capaz de garantir a aprendizagem.
\end{abstract}

Palavras-chave: Discurso da Educação Matemática. Docência. Anos Iniciais do Ensino Fundamental. Michel Foucault.

\begin{abstract}
The article problematizes statements that make up the discourse of Mathematics Education and its truth effects on the pedagogical practices of teachers who work in the Early Years of Elementary Education. The theoretical contributions that underpin the investigation are the theories of Michel Foucault, especially the concepts of discourse and statement. The research material is composed of interviews with teachers of the 3rd or 4th year in

\footnotetext{
* Doutora em Educação pela Universidade do Vale do Rio dos Sinos (UNISINOS). Professora permanente do Programa de Pós-Graduação em Educação da Universidade Federal do Rio Grande do Sul (UFRGS), Porto Alegre, Rio Grande do Sul, Brasil. Endereço para correspondência: Rua Inácio Vasconcelos, 40. Apto 1003. Bairro Boa Vista, Porto Alegre, Rio Grande do Sul, Brasil, CEP: 90480-160. E-mail: fernandawanderer@gmail.com.

** Mestre em Educação pela Universidade Federal do Rio Grande do Sul (UFRGS). Professora da rede privada de ensino da cidade de Porto Alegre, Rio Grande do Sul, Brasil. Endereço para correspondência: Rua Francisco Petuco, 45. Apto 806 B4. Bairro Boa Vista, Porto Alegre, Rio Grande do Sul, Brasil, CEP: 90520-620. E-mail: fernandalongo25@gmail.com.
} 
the private school network of Porto Alegre. The analytical strategy used to examine the material was guided by the discourse analysis from Michel Foucault's perspective. The material examination evidenced the presence of two statements constituting the discourse of Mathematical Education in the Early Years: "the importance of the use of concrete material and digital resources in Mathematics classes" and "the relevance of the registration and formalization of mathematical knowledge as a guarantee of learning". Thus, it can be concluded based on the interviews carried out, that mathematics teaching in the Early Years is supported by statements that are part of different discursive fields, but predominate those based on Platonic constructivism and ideals, leading the pedagogical processes in an ascending way: concrete materials for systematization and formalization, making this final stage as the most relevant and capable of ensuring learning.

Keywords: Discourse of Mathematics Education. Teaching. Initial Years of Primary Education. Michel Foucault.

\section{Introdução}

O artigo problematiza enunciados que conformam o discurso da Educação Matemática e seus efeitos de verdade sobre as práticas pedagógicas das professoras que atuam nos Anos Iniciais do Ensino Fundamental. Para isso, foram realizadas entrevistas com educadoras que lecionam nos Anos Iniciais de escolas da rede privada de ensino do município de Porto Alegre, no Estado do Rio Grande do Sul. Os aportes teóricos que sustentaram a análise situam-se no pensamento de Michel Foucault, basicamente suas reflexões sobre discurso e enunciado.

O texto está divido em cinco seções. A primeira consiste nesta breve introdução. A segunda seção destaca os referenciais teóricos do artigo. A terceira apresenta e discute os caminhos metodológicos realizados para a geração do material empírico escrutinado. Os resultados da análise conformam a quarta seção. E, a última, aborda algumas implicações do estudo para a área da Educação Matemática.

\section{Aportes teóricos}

Nos últimos anos, a área da Educação Matemática tem se servido das ferramentas foucaultianas para discutir e problematizar questões que envolvem tanto o currículo escolar (KNIJNIK, 2012; KNIJNIK; WANDERER, 2015), como as relações mais amplas entre o conhecimento matemático e a sociedade neoliberal (VALERO, 2013; KNIJNIK, 2017; SANTOS, 2019). Nessas pesquisas, os conceitos foucaultianos de discurso, governamentalidade, relações de poder/saber e regimes de verdade, basicamente, constituíram-se em vetores analíticos com o propósito de potencializar reflexões desenvolvidas em diferentes formas de vida, incluindo a escolar. 
O presente artigo insere-se nesse solo teórico, compreendendo a Educação Matemática como um discurso constituído por um conjunto de enunciados que produzem verdades sobre os processos de ensinar e aprender Matemática. Para efeito, a noção de discurso, discutida por Michel Foucault (2007), está fortemente sustentada nas reflexões sobre enunciado.

Para o filósofo, o enunciado não necessariamente é um ato de fala, ou seja, “[...] uma fotografia ou um mapa podem ser um enunciado, desde que funcionem como tal, ou seja, desde que sejam tomados como manifestações de um saber e que, por isso, sejam aceitos, repetidos e transmitidos" (VEIGA-NETO, 2007, p. 94). Estamos tratando de um ato raro, que não é facilmente visto, mas torna-se visível nas recorrências daquilo que é dito.

Podemos afirmar que alguns dos enunciados que sustentam o discurso da Educação Matemática contemporânea são: “aprender matemática é difícil”, “"é importante trabalhar com a realidade nas aulas de matemática" e "para aprender matemática é preciso usar materiais concretos". Estes enunciados produzem efeitos de verdade em quem ouve e em quem fala. Enunciados que, de tanto serem repetidos em diferentes instâncias e por diferentes vozes, acabam reforçando ou atenuando outros enunciados, constituindo, nesse caso, o discurso da Educação Matemática.

Na obra A Ordem do Discurso (FOUCAULT, 1996), Foucault mostra que existem diversos procedimentos que controlam, selecionam, regulam a produção de discursos na sociedade, permitindo que determinadas práticas e saberes se naturalizem sem serem questionados. Seguindo Foucault, Sommer (2007) nos ajuda a refletir que há certa ordem do discurso da Educação (Matemática) circulando nas escolas e, de modo mais amplo, na própria sociedade. Isso significa dizer que há "[...] regras que sancionam ou interditam a produção e a circulação de práticas discursivas escolares” (SOMMER, 2007, p. 58), que conformam determinados enunciados em detrimento de outros e que acabam por produzir formas de se dizer e ver a sala de aula, os alunos e, em especial, a aula de Matemática.

Assim, compreender a Educação Matemática como um discurso que forma os objetos de que falam, no sentido empreendido por Foucault, é ponto de partida para a escrita deste artigo. Os estudos foucaultianos nos possibilitam pensar que somos regulados e constituídos continuamente pelos discursos que nos perpassam, regulam nossa forma de ser e de agir. Para o filósofo (FOUCAULT, 2007), o discurso vai além do que é dito, além do que é visível a 'olho nu', sendo compreendido como práticas que formam e regulam as formas de agir em diferentes formas de vida, como aquelas presentes na rede privada de ensino de Porto Alegre. 
Nessa esteira, algumas pesquisas já foram realizadas com o intuito de problematizar enunciados que constituem o discurso da Educação Matemática, como mostram os estudos de Valero (2013), Knijnik e Duarte (2010) e Knijnik e Wanderer (2007). Valero (2013), ao investigar o discurso da Educação Matemática escolar em suas relações com a sociedade neoliberal, destaca que os conhecimentos científico e matemático são significados como promessa para o desenvolvimento social, econômico e cultural de uma sociedade. Segundo a autora, o enunciado "a educação matemática é para todos" configura-se como uma declaração recente, que surge na década de 1980, pois antes disso não havia o questionamento da necessidade de existirem sujeitos que dominassem a Matemática, como engenheiros e cientistas, posicionados como os responsáveis pelo “[...] grande progresso tecnológico que fez o mundo atingir este ponto de desenvolvimento - e de decadência também" (VALERO, 2013, p. 3). Dessa forma, pensar na escola sem a presença da Matemática e da Ciência, com todas as suas aplicações tecnológicas, tornou-se impraticável. Com a mudança da racionalidade moderna para a racionalidade neoliberal, a ideia de que a Matemática deve ser ensinada a todos vem na carona do pensamento de que a Matemática garantiria a competitividade do país na economia global. Esse movimento teria uma visão normativa, orientando políticas públicas, por exemplo, para ampliar o alcance de todos à Matemática escolar.

Outro enunciado muito presente no discurso da Educação Matemática, estudado por Knijnik e Duarte (2010), é aquele que diz sobre “a importância de trazer a 'realidade' para as aulas de matemática". As autoras analisaram anais de eventos nacionais com enfoque na Etnomatemática e, dessa forma, na busca pelo que é recorrente, evidenciaram que esse enunciado tem bastante força no discurso da Educação Matemática. Elas perceberam que o "trazer a realidade" justificaria a incorporação de diferentes contextos em sala de aula com o enfoque na assimilação de conteúdos com mais facilidade. Assim, enfatizam que o movimento de trazer a realidade do aluno para a escola está vinculado ao propósito de ensinar os jogos de linguagem da escola, não para valorizar ou legitimar a cultura dos alunos.

Especificamente nos Anos Iniciais do Ensino Fundamental predomina um enunciado que afirma: "é importante trabalhar com materiais concretos nas aulas de matemática", problematizado por Knijnik e Wanderer (2007). Segundo elas, os materiais manipuláveis ganham um espaço considerável nas orientações para o ensino de Matemática nos Anos Iniciais, servindo como ponte entre o "concreto" e o "abstrato". Dessa forma, torna-se quase obrigatório construir esta ponte durante as aulas, admitindo-se que apenas se aprende o abstrato a partir da sua relação com o concreto. Esta verdade posiciona os conceitos matemáticos como únicos, universais e não construídos conforme o contexto em que se 
desenvolvem.

Os trabalhos acima serviram de inspiração para a composição desta investigação. Assim como nas pesquisas descritas, em nosso estudo buscamos analisar o discurso da Educação Matemática assumindo que existiram condições de possibilidade para a constituição de práticas discursivas que fizeram sentido em um determinado tempo e espaço. Na próxima seção, destacamos o material empírico examinado e a metodologia empreendida para a realização da pesquisa que envolveu um grupo de professoras que atuam nos Anos Iniciais do Ensino Fundamental.

\section{Metodologia}

A pesquisa que gerou a escrita deste artigo pode ser considerada como um estudo de caso qualitativo (ANDRÉ, 2013). A parte empírica envolveu um grupo de professoras que lecionavam, em 2017, nos $3^{\circ}$ e $4^{\circ}$ anos do Ensino Fundamental de escolas da rede privada de Porto Alegre. A escolha dessas séries justifica-se por ser uma etapa importante de sistematização dos conhecimentos matemáticos apresentados nos Anos Iniciais. Essa faixa etária fica responsável pela "progressiva sistematização" das experiências desenvolvidas na Educação Infantil bem como por "[...] novas formas de relação com o mundo, novas possibilidades de ler e formular hipóteses sobre os fenômenos, de testá-las, de refutá-las, de elaborar conclusões" (BRASIL, 2018, p. 55-56).

Ao todo, participaram da investigação quatro educadoras que trabalhavam em mais de uma escola da rede, aqui denominadas de forma fictícia por: Paula, Julia, Helena e Gabriela. O quadro 1 abaixo mostra algumas características das mesmas:

\begin{tabular}{|c|c|c|c|}
\hline Nome & Formação & $\begin{array}{c}\text { Tempo de } \\
\text { atuação no } \\
\text { magistério }\end{array}$ & $\begin{array}{c}\text { Ano/turmas em que } \\
\text { lecionava }\end{array}$ \\
\hline Paula & $\begin{array}{c}\text { Pedagogia e } \\
\text { Ciências Sociais }\end{array}$ & 16 anos & $4^{\circ}$ ano (duas turmas) \\
\hline Julia & $\begin{array}{c}\text { Pedagogia e } \\
\text { Letras }\end{array}$ & 8 anos & $4^{\circ}$ ano (duas turmas) \\
\hline Helena & Pedagogia & 25 anos & $3^{\circ}$ ano e $4^{\circ}$ ano \\
\hline Gabriela & Pedagogia & 9 anos & $1^{\circ}$ ano e $4^{\circ}$ ano \\
\hline
\end{tabular}

Quadro 1 - Dados das entrevistadas

Fonte: Elaborado pelas autoras 
As instituições de ensino onde as entrevistadas lecionavam não eram, segundo elas, capturadas por avaliações externas como a Prova Brasil ou o PISA, mas respondiam à necessidade das aprovações nas universidades (principalmente as federais) através do Exame Nacional do Ensino Médio (ENEM) e dos vestibulares. As escolas tinham uma boa infraestrutura e bastante material pedagógico à disposição, pois consideravam que um ensino de qualidade levava em conta uma infraestrutura adequada.

O contato com as educadoras que participaram do estudo foi facilitado pelo fato de uma de nós atuar como docente em escolas da rede privada de Porto Alegre. Assim, ao explicar melhor do que se tratava a pesquisa e mostrar o roteiro de questões para a entrevista, todas aceitaram participar e assinar o Termo de Consentimento Livre e Esclarecido. A entrevista tinha alguns tópicos, planejados previamente: a) Trajetória pessoal e formação da entrevistada; b) Opinião da professora sobre lecionar Matemática; c) Recursos utilizados no ensino da Matemática; d) Estratégias que funcionam melhor com crianças desta faixa etária $\left(3^{\circ}\right.$ e $4^{\circ}$ anos); e) Facilidades e dificuldades percebidas no processo de aprendizagem da Matemática pelos alunos; f) Atividades mais significativas neste processo. Cada entrevista teve duração média de 40 minutos e, ao todo, foram transcritas duas horas de gravação. Em alguns casos, foi realizada mais de uma entrevista com a mesma participante, a fim de complementar algumas discussões iniciadas e rever pontos que foram pouco discutidos.

A escolha pelas entrevistas foi mobilizada em função da necessidade de mapear práticas e enunciações acerca do ensino de Matemática nos Anos Iniciais. Autores como Paz e Frade (2016) destacam que a entrevista consiste em um dos melhores recursos capazes de apreender os sentidos atribuídos pelos sujeitos, no nosso caso, as professoras, às suas realidades, seus modos de ver e conceber as práticas pedagógicas que produzem nas escolas e àquilo que pensam sobre a Educação Matemática que praticam.

As entrevistas ocorreram, a pedido das professoras, nas escolas onde trabalhavam. Mesmo com um "roteiro", não tínhamos a pretensão de segui-lo "à risca", já que nosso objetivo era "[...] propor aos entrevistados uma espécie de exercício de lacunas a serem preenchidas" (SILVEIRA, 2007, p. 140). As participantes do estudo sempre se mostraram muito receptivas e dispostas a falar o que pensavam sobre Matemática, sobre as estratégias que utilizam em suas aulas e sobre a disciplina de Matemática nos Anos Iniciais. Ao narrar suas concepções, suas práticas e suas verdades, os sujeitos submetem-se a um conjunto de regras, um determinado ambiente e a uma determinada cultura, permitindo uma análise, mesmo que efêmera, das formas de se ensinar Matemática. 
Realizamos a escuta atenta - mais de uma vez - do material e tentamos organizar agrupamentos temáticos, a partir do referencial teórico apresentado, atribuindo-lhes sentido. O conjunto de falas das professoras foi sendo examinado de acordo com a análise do discurso, como discutido anteriormente, com a intenção de delinear alguns enunciados que têm se naturalizado como verdadeiros no ensino de Matemática.

A partir dos saberes recorrentes, que aparecem na transversalidade das frases, também se torna possível perceber as dispersões, ou seja, aquilo que, de certa forma, se singulariza, as continuidades/descontinuidades que os enunciados mantêm com outros enunciados. Foucault (2007) assume a dispersão como o que não há de comum entre os enunciados, aquilo que não é abraçado pela regra. Assim, não se trata de encontrar explicações nas falas das participantes, mas de descrever o que dizem, já que as enunciações narram uma forma de vida específica, que responde às regras dos jogos de linguagem que a formam.

A análise realizada, na continuidade do texto, em momento algum é interna ao discurso, como se este pudesse ser desvendado em sua essência. Pretendemos, a partir de sua exterioridade, analisar a teia discursiva que dá sentido às enunciações das professoras, que as colocam na posição de sujeito da Educação Matemática. Dessa forma, trata-se de examinar quais regras estão sendo colocadas em funcionamento para que as professoras possam falar sobre a Educação Matemática, formular determinadas perguntas e ocupar uma determinada posição no interior deste discurso. O resultado desse exercício analítico será apresentado a seguir.

\section{As docências em Matemática nos Anos Iniciais}

Nesta seção, evidenciamos os enunciados que conformam o discurso da Educação Matemática que circula nos Anos Iniciais das escolas privadas de Porto Alegre. Os enunciados problematizados aqui, dentre outros, acabam por prescrever formas de agir e regulam escolhas pedagógicas nas aulas de Matemática (AURICH; BELLO, 2018). Tais prescrições tanto incluem, quanto excluem determinadas práticas, visibilizando e inibindo certas formas de ser professor. Cabe ressaltar que não se trata, com essa analítica, de desvendar uma suposta verdade sobre o ensino de Matemática, ou buscar por sua essência, "[...] mas, a partir do próprio discurso, da sua aparição e de sua regularidade, passar às suas condições externas de possibilidade" (FOUCAULT, 1996, p. 53).

Tendo isso presente, buscamos atribuir alguns sentidos ao material examinado, assumindo uma vontade ética de entender a condução de processos pedagógicos vinculados a 
um determinado regime de verdade. A análise mostrou a presença de dois enunciados: "a importância do uso do material concreto e dos recursos digitais nas aulas de Matemática" e "a relevância do registro e da formalização do conhecimento Matemático como garantia da aprendizagem”. Ambos serão descritos e problematizados nas subseções a seguir.

\subsection{A importância do uso do material concreto e dos recursos digitais nas aulas de Matemática}

Uma forte recorrência evidenciada nas entrevistas das educadoras refere-se à presença dos materiais manipuláveis no ensino de Matemática nos Anos Iniciais. Em diferentes momentos, elas mencionaram a necessidade de trabalhar em sala de aula com os chamados materiais concretos. Os excertos abaixo mostram essa relação:

A gente tenta usar vários materiais, eu gosto bastante do material concreto, que é a base 10. A gente trabalha também com ábaco, tem trabalhado pouco, mas a gente trabalha. A gente trabalha com QVL [quadro valor-lugar], que também faz com que o aluno entenda a questão da posição do valor do numeral, enfim, e a gente trabalha com outros materiais. [...] Trabalhamos com a tabela pitagórica, trabalhamos com livrinhos, vários materiais [...].

(Entrevista com Gabriela, 2017).

Eu acho que a gente tem que fazer uma mistura dos recursos mais lúdicos, uma aula mais lúdica, mais concreta, que vá para o concreto, que vai relacionar com o dia a dia e usar aquele método mais tradicional mesmo, mais de sistematização no caderno. Eu acho que tem que ter os dois, [...] aqueles que têm mais dificuldade precisam de coisas mais objetivas, mais básicas e nós temos que realmente fazer o aluno refletir mais sobre a matemática e botar ela para o dia a dia. [...] Eu gosto de fazer essa relação mais concreta com os alunos, que eles tenham esse tipo de conhecimento, mas sem deixar o método um pouco mais tradicional de sistematização, principalmente pensando no aluno que precisa.

(Entrevista com Julia, 2017).

Quando o aluno tem dificuldade eu acho importante uma intervenção de desenhar, o Material Dourado ou alguma coisa assim, ele dá um clique.

(Entrevista com Paula, 2017).

Os fragmentos acima evidenciam o quanto as professoras utilizam-se de diferentes e diversos materiais, ou seja, ábaco, Material Dourado, desenho e livrinhos como forma de garantir a aprendizagem de conteúdos da Matemática escolar, uma vez que o uso desses materiais é associado aos momentos de construção do conhecimento. Mais do que isso, para elas essa garantia ocorre pelo fato dos materiais potencializarem a passagem do concreto (manuseio de objetos) para o próximo estágio, a abstração, permitindo aos estudantes a compreensão desse processo. Como expressou Gabriela: "O primeiro ano trabalha tudo com material concreto, porque na verdade eles estão na fase da construção" (Entrevista com Gabriela, 2017). E, a partir do $3^{\circ}$ ano: "quando eles começam a entender o processo, a gente começa então a deixar o material concreto de lado e eles já vão pra parte da abstração" 
(Entrevista com Gabriela, 2017).

A imperatividade do uso dos materiais concretos foi observada nas gramáticas dos Anos Iniciais, da Educação Matemática para jovens e adultos, na Educação do Campo, na Educação de Surdos, enfim, da Matemática escolar (KNIJNIK; WANDERER, 2007; KNIJNIK et al., 2012; WANDERER; CARNEIRO, 2016). Por mais que estas áreas sejam de diferentes espaços, a relevância dos materiais para a construção do conhecimento e o uso do concreto para sanar as dificuldades de aprendizagem dos alunos é uma regra que tem se instituído e circulado no discurso da Educação Matemática proveniente das teorias construtivistas, como apresentam Knijnik e Wanderer (2007).

Em nosso estudo, além de apontar as fortes relações desse enunciado - a importância do uso de materiais concretos nas aulas de Matemática - com as ideias de Piaget sobre o processo de aprendizagem, apresentamos também os fortes vínculos com o pensamento de Rousseau (2004). Ao dizer, na obra intitulada Émile ou De l'éducation, que Emílio não deve ser ensinado, o filósofo coloca as balizas para o pensamento pedagógico desenvolvido por Pestalozzi e por Piaget, que entendem que o professor não é mais o preceptor (aquele que dá preceitos) ou o mestre (aquele que ensina) dos alunos, mas alguém que conduz o estudante até o desenvolvimento do conhecimento de si e dos outros.

Nesse processo, que Rousseau (2004) chama de "educação natural”, o adulto manipula o meio para que o estudante possa agir e se desenvolver enquanto ser humano de forma livre e autônoma (SANTA, 2020). É possível ver que este pensamento muito se aproxima das enunciações das professoras apresentadas anteriormente. Ao dizer que o aluno deve construir os conceitos, que quando tem dificuldade o adulto deve fazer a "intervenção", o educador está sendo posicionado como um mediador da aprendizagem, reforçando a ideia do uso de diferentes materiais para que a aprendizagem de fato aconteça.

Outro aspecto presente em nosso estudo é o forte entrelaçamento entre o enunciado "é importante trabalhar com materiais concretos nas aulas de Matemática" com o que diz "é relevante usar as tecnologias na escola". Nas falas a seguir, podemos perceber que os alunos dos Anos Iniciais, na rede privada, são posicionados como sujeitos tecnológicos. Desta forma, os recursos digitais (o computador, a calculadora) estão no rol de falas das entrevistadas como mais um apoio ao aprendizado do aluno:

A gente trabalha às vezes integrado ao trabalho da informática, dai, então, a professora de informática, dependendo do que nós estamos trabalhando, algumas situações, ela usa. Calculadora a gente não usa muito, a gente quase não usa. Isso até é bem legal, de repente de usar, mas a gente não usa... porque eles são tecnológicos!

(Entrevista com Gabriela, 2017). 
Eu tenho recursos digitais nas duas escolas e eu tenho livros didáticos que eu gosto muito [...] eu vejo como foram bons professores de matemática que fizeram esses materiais e que realmente me auxiliam a dar uma aula melhor. Então nem é tanto mérito meu, mas também de onde eu falo. Eu estou há oito anos numa escola particular e três na outra e eu sinto que realmente eu fui beneficiada como docente com esse tipo de recurso que eu tenho nas duas escolas. Eu tenho um livro digital, eu tenho o projetor [...]

(Entrevista com Julia, 2017).

Ao longo das entrevistas, todas as professoras destacaram a presença de artefatos tecnológicos, principalmente os computadores, como recurso em suas aulas de Matemática. Com o acesso fácil às tecnologias educacionais, o material concreto ganha novos portadores, como os recursos digitais. Nos documentos do Ministério da Educação, em especial nas Diretrizes Curriculares Nacionais, aparece a importância de se oferecer processos formativos aos professores para um uso mais efetivo dos recursos digitais em sala de aula a fim de aproximar aluno e professor:

É importante que a escola contribua para transformar os alunos em consumidores críticos dos produtos oferecidos por esses meios, ao mesmo tempo em que se vale dos recursos midiáticos como instrumentos relevantes no processo de aprendizagem, o que também pode favorecer o diálogo e a comunicação entre professores e alunos. Para tanto, é preciso que se ofereça aos professores formação adequada para o uso das tecnologias da informação e comunicação e que seja assegurada a provisão de recursos midiáticos atualizados e em número suficiente para os alunos (BRASIL, 2013, p. 111).

As enunciações presentes nas Diretrizes aproximam-se muito das falas das educadoras, principalmente quando Julia diz que o uso do recurso digital "realmente auxilia a dar uma aula melhor" e, ao mesmo tempo, se sente "beneficiada como docente com esse tipo de recurso". Dessa forma, Julia toma a verdade de que a aula fica melhor com o uso de materiais, sejam eles concretos ou digitais, fazendo-a se sentir beneficiada como docente. Para Foucault (2004, p. 282), essa relação do sujeito com a verdade é um jogo, “[...] um conjunto de procedimentos que conduzem a um certo resultado, que pode ser considerado, em função de seus princípios e das suas regras de procedimento, válido ou não, ganho ou perda”.

Nas entrevistas que realizamos, as educadoras destacam que as tecnologias "favorecem", "facilitam" ou "estimulam" o ensino de Matemática. Santos (2009) examina investigações que consideram as Tecnologias da Informação e Comunicação (TIC's) como agentes mediadores e potencializadores da aprendizagem em Matemática. A autora percebe que no discurso da Educação Matemática contemporânea emergem enunciações vinculadas a uma necessidade de inovação do ensino da Matemática sempre vinculada ao uso das tecnologias. Ainda em consonância com Santos (2009), pode-se dizer que as pesquisas sobre as tecnologias na escola esboçam um perfil de professor de Matemática inovador, que renova a sua prática para responder a uma cultura informatizada. 
Os resultados encontrados por Santos (2009) pouco diferem dos presentes no estudo de Milano et al. (2016), no qual foram examinados artigos da Revista BOLEMA (Boletim de Educação Matemática), publicados entre 2010 e 2016, que articulavam a Educação Matemática com as tecnologias. Os autores destacam que uma das recorrências encontradas diz respeito ao uso dos recursos digitais como uma forma de "[...] despertar nos alunos o interesse pelo conhecimento, proporcionando significado ao aprendizado" (MILANO et al., 2016, p. 100). Outra recorrência foi o fato de a tecnologia ser um recurso que atribui sentido aos conteúdos que eram trabalhados desde uma perspectiva tradicional. Dessa forma, a investigação reforça a ideia de que a articulação entre a inovação tecnológica e a Educação Matemática promove uma educação com mais qualidade, satisfazendo as necessidades atuais do país.

Com efeito, a Base Nacional Comum Curricular (BNCC) também incentiva o uso da tecnologia como uma ferramenta importante no processo do ensino de Matemática. No documento há uma forte indicação aos professores: "Utilizar processos e ferramentas matemáticas, inclusive tecnologias digitais disponíveis, para modelar e resolver problemas cotidianos, sociais e de outras áreas de conhecimento, validando estratégias e resultados". (BRASIL, 2018, p. 265). Além disso, a BNCC orienta que:

Os recursos didáticos como malhas quadriculadas, ábacos, jogos, livros, vídeos, calculadoras, planilhas eletrônicas e softwares de geometria dinâmica têm um papel essencial para a compreensão e utilização das noções matemáticas. Entretanto, esses materiais precisam estar integrados a situações que levem à reflexão e à sistematização, para que se inicie um processo de formalização (BRASIL, 2018, p. 274).

Levando em conta as discussões propostas até o momento, identificamos fortes semelhanças nas enunciações acerca do uso do material concreto e dos recursos digitais, já que ambos são colocados como apoio, como facilitadores do processo de aprendizagem dos conteúdos da Matemática escolar. É possível perceber, também, que essas implicações têm efeitos no espaço investigado. As educadoras entrevistadas significam o uso das tecnologias como um bom recurso a ser usado nas aulas de Matemática. É dado aos artefatos tecnológicos um significativo valor, que faz com que pensem que suas aulas ficam melhores. Nenhuma delas apresentou argumentos ou considerações contrárias a esse uso.

Os enunciados referentes ao uso do material concreto, incluindo os recursos digitais, funcionam como peças de uma mesma engrenagem que se alimentam de forma indissociável, de modo a nos fazer perceber o quanto os sujeitos desta pesquisa estão capturados pelos discursos dos quais estes enunciados fazem parte. Ao mesmo tempo, tanto as educadoras entrevistadas, quanto documentos oficiais, como a Base Nacional Comum Curricular 
(BNCC), mostram que o uso dos recursos didáticos serve para levar a situações de sistematização, etapa fundamental no processo de formalização que irá conduzir à abstração, tema discutido na próxima seção.

\subsection{A relevância do registro e da formalização do conhecimento matemático como garantia da aprendizagem}

Outra recorrência evidenciada no exame das entrevistas das educadoras refere-se à relevância da sistematização nas aulas de Matemática dos Anos Iniciais, aqui compreendida como a possibilidade de registar as ideias matemáticas usando a linguagem apropriada. Isso nos leva a pensar que a finalidade do processo de ensino em Matemática no contexto pesquisado é a formalização como etapa para alcançar a abstração. Para isso, investe-se no registro. Os excertos abaixo indicam essa questão:

Lá no algoritmo eles precisam também mostrar de que forma pensam, então tem que ter também um modelo do professor, tem que ir pra quadro, tem que fazer, ai eles fazem o registro coletivo, [...] eu acho que é importantíssimo, até por que alguns alunos, não a maioria, mas alguns, voltam às vezes para a pasta e pegam o registro para olhar [...].

(Entrevista com Gabriela, 2017).

Eu acho que a criança deve saber todas as quatro operações, que é o básico, a técnica operatória... tem que saber o que aquilo significa, o que cada parte significa, que aquele 2 é duas dezenas e não é 2 unidades, enfim... Eu digo a técnica no sentido de ele identificar, usar o raciocínio, não sei como é que a gente diria isso...

(Entrevista com Paula, 2017).

Tenho uma experiência que eu faço e acho que dá resultado: eles [os alunos] leem matemática. Pergunto "o que tu fez, 'ah eu agrupei aqui', porque tu agrupou? Então escreve isso'”. Eu consegui que um aluno entendesse a divisão desta forma. Ele não conseguia entender a técnica. 'Então tu escreve: por que tu fez isso? Qual foi o segundo passo? E o terceiro? Tem crianças que têm que entender que eles podem ler matemática. Eu acho que é importante esse registro, acho importante.

(Entrevista com Helena, 2017).

A necessidade da formalização é uma ideia que se apresenta de forma recorrente nas falas das entrevistadas, as quais destacam a necessidade dos registros, sejam seguindo modelos apresentados pelos professores ou as técnicas de calcular. Estas ideias não são novas. Cabe perguntar as razões de continuarem tendo tanta força, mesmo após a emergência de teorizações que consideram o conjunto de conhecimentos matemáticos como uma prática social, que procura valorizar diferentes formas de pensar e de fazer Matemática, como os estudos da Etnomatemática.

A abstração e a formalização remontam a uma postura platônica de enxergar a 
Matemática como aquilo que existe independente dos seres humanos. Quartieri (2012) realiza uma discussão que nos ajuda a compreender as semelhanças de família que os jogos de linguagem emergentes das falas das educadoras mantêm com a filosofia de Platão.

Segundo a autora, a Matemática era concebida como uma verdade independente de qualquer verificação empírica e os objetos matemáticos serviriam de modelo ao mundo. Assim, o estudante de Matemática não criava os objetos dos quais falava, mas os descobria já que os mesmos estavam em algum lugar prontos para isso. Dessa forma, o verdadeiro conhecimento estaria na ideia, concebida como a essência das coisas e dos conceitos. "A Matemática era considerada um elemento fundamental para todos, sendo concebida como um conhecimento importante não pelo valor prático, mas pela sua capacidade de acessar o potencial do ser humano" (QUARTIERI, 2012, p. 154). Além disso, a filosofia platônica posiciona o conceito, a ideia como "[...] uma verdade atemporal, universal, que o pensamento descobre por meio da razão" (QUARTIERI, 2012, p. 141).

Autores como Quartieri (20102), Damazio Júnior e Venson (2019) destacam em seus estudos as fortes semelhanças de família entre os conhecimentos matemáticos e a hegemonia da Ciência Moderna. Para eles, a Ciência Moderna posiciona a Matemática em um lugar central que acaba por instituir duas verdades bastante fortes, a saber: conhece-se algo a partir do momento que se quantifica este algo; se algo não é quantificável, significa que não é cientificamente relevante. Dessa forma, pode-se entender a posição que a Matemática tem até hoje como a "rainha das ciências" (WALKERDINE, 1995, p. 5), já que, em momentos diferentes da história da humanidade é associada à inteligência de um sujeito.

As falas das professoras que integraram a pesquisa demonstram a presença do formalismo no contexto pesquisado. Elas se referem ao registro, à relevância do modelo a ser seguido para potencializar a abstração. "Seguir um modelo" é uma das regras que conformam o discurso da Educação Matemática que emerge do formalismo, fortemente associado aos princípios das filosofias de Platão e Kant (MONTEIRO; POMPEU, 2001).

Enquanto o formalismo kantiano consiste em imitar ou prever um comportamento humano a partir de um modelo, o formalismo platônico postula que o conjunto de conhecimentos (matemáticos) é pré-existente ao mundo. Ambos, entretanto, sustentam que a Matemática é única e que todos podem chegar a mesma e exata conclusão. Para os autores, o formalismo produz a noção de que o trabalho do matemático é gerar teorias formais consistentes capazes de alcançar a formalização completa da Matemática. Partindo disso, Quartieri (2012) destaca que o formalismo, na escola, se manifesta, dentre outras, através da repetição de exercícios. 
As professoras entrevistadas em nosso estudo se referem, muitas vezes, à palavra "repetição" como forma de garantir a aprendizagem dos alunos. O relato de Gabriela é emblemático: "Quando a grande maioria [dos alunos] constrói o conceito é porque as coisas aconteceram" (Entrevista com Gabriela, 2017). Porém, segundo ela: "Mesmo com material concreto, com exploração no quadro, com atendimento individual, alguns não conseguem... então tu vais ter que achar uma outra estratégia, ou de novo repetir, porque alguns alunos precisam de muita repetição pra tu chegar neles" (Entrevista com Gabriela, 2017).

Essa repetição, para Giongo (2008), seria uma das regras da gramática da disciplina Matemática, cujo treino levaria ao padrão de verdade incontestável e à certeza. Dessa forma, quem dominar as técnicas e regras que conformam a linguagem da Matemática escolar acaba por legitimar o que pode ser dito - e escrito - ou não. Assim, a repetição, o treino, a sistematização e a técnica passam a ser prescrições pedagógicas no contexto pesquisado. Sistematiza-se para se ter certeza de que o aluno entendeu. Repete-se para saber se a dificuldade do aluno é pontual. Essas ideias fortalecem e legitimam os ideais do racionalismo kantiano, criando condições de possibilidade para que elas se reatualizem constantemente.

As fortes características da Matemática escolar, que surgiram do escrutínio do material de pesquisa, demonstram que a abstração tem um espaço bastante significativo no interior do discurso da Matemática escolar. Usando as discussões de Walkerdine (1995), Giongo (2008) e Quartieri (2012), é possível dizer que as enunciações das entrevistadas são ressonâncias de verdades, no sentido de Foucault, há muito tempo consolidadas na área da Educação Matemática, as quais reforçam a necessidade de se trabalhar com materiais concretos e, ao mesmo tempo, garantir a abstração.

Essas verdades situam-se em uma rede discursiva que emerge do campo pedagógico e também das políticas públicas. Com efeito, na parte que explicita os princípios da Matemática nos Anos Iniciais, a BNCC legitima o exposto até aqui, já que “[...] orienta-se pelo pressuposto de que a aprendizagem em Matemática está intrinsecamente relacionada à compreensão, ou seja, à apreensão de significados dos objetos matemáticos, sem deixar de lado suas aplicações" (BRASIL, 2018, p. 274).

Poderia-se esperar que, a partir da potência com que a formalização e a abstração apresentaram-se nas análises até aqui empreendidas, a assepsia também surgiria como uma regra que conforma a gramática da disciplina Matemática na rede privada de Porto Alegre, mas as enunciações das entrevistadas demonstram que essa é uma dissonância em relação aos 
estudos realizados até aqui (GIONGO, 2008).

Observemos, nas vozes das entrevistadas, que, ao tratar do registro, a escrita não precisa seguir as regras próprias da linguagem matemática praticada na academia. Helena, ao expressar como avalia as formas dos alunos registrarem as operações, disse: “ $E$ válida toda a forma, cada criança tem um caminho para chegar na resposta certa, mas eu acho que tem que ter um registro igual" (Entrevista com Helena). Já Gabriela expressou que: "Alguns alunos precisam de registro, mas tem outros que vão de outras formas, também não pode deixar de aceitar [...] são diferentes estratégias, mas que chegam num resultado, acho que a gente tem que valorizar esses tipos diferentes de caminhos" (Entrevista com Gabriela, 2017).

A assepsia, ou seja, a realização de exercícios que seguem uma ordem e usam uma linguagem própria, de acordo com Giongo (2008), estaria a serviço da exclusão da sujeira que contaminaria o currículo da Matemática. A autora pontua que a Matemática é considerada imanente e indissociável dos propósitos e marcas culturais do contexto de que faz parte. É importante destacar que, em nosso estudo, em momento nenhum das entrevistas a necessidade do registro foi questionada, apenas a forma como esse registro tem sido exigido. Assim, verifica-se uma ruptura no que vinha sendo dito e feito no campo da Matemática escolar nesta faixa etária a partir do momento em que o modelo e a assepsia passam a ser questionados e ressignificados.

Retornando às enunciações da pesquisa, vemos que as professoras estão esmaecendo a necessidade de registrar os conhecimentos estudados sempre de acordo com o modelo, nos levando a pensar que a assepsia é uma regra questionada no contexto dos Anos Iniciais. Por outro lado, a partir do momento que se valoriza "diferentes estratégias, mas que chegam num resultado" (Entrevista com Gabriela), as professoras estão, mais uma vez, legitimando a ideia de que cada um "constrói” o conjunto de conhecimentos matemáticos do seu jeito, e elas estão oferecendo oportunidades para tal.

Talvez esse esmaecimento da necessidade de registrar os conhecimentos matemáticos sempre de acordo com o modelo encontre sustentação nas orientações de documentos oficiais recentes, como a BNCC:

\footnotetext{
Apesar de a Matemática ser, por excelência, uma ciência hipotético-dedutiva, porque suas demonstrações se apoiam sobre um sistema de axiomas e postulados, é de fundamental importância também considerar o papel heurístico das experimentações na aprendizagem da Matemática. [...] Os processos matemáticos de resolução de problemas, de investigação, de desenvolvimento de projetos e da modelagem podem ser citados como formas privilegiadas da atividade matemática, motivo pelo qual são, ao mesmo tempo, objeto e estratégia para a aprendizagem ao longo de todo o Ensino Fundamental (BRASIL, 2018, p. 263).
}

Isso significa dizer que os documentos já trazem novos contornos para algumas das 
regras do formalismo na sala de aula. Instituir como estratégia de ensino o desenvolvimento de projetos ou a Modelagem Matemática significa romper com a assepsia, que exige um aprendizado sem erros, com os registros de todos os alunos realizados da mesma forma. Ao realizar um projeto ou uma experimentação, o erro faz parte do processo e é admitido como algo benéfico nessa lógica. Dessa forma, mesmo que o objetivo seja o formalismo, abre-se o leque de possibilidades e conjura-se uma nova regra, que pode possibilitar singularidades na docência em Matemática.

Como esperamos ter conseguido demonstrar, a Matemática escolar que vem sendo produzida em algumas escolas da rede privada de Porto Alegre/RS responde a alguns enunciados presentes no discurso da Educação Matemática: "a importância do uso dos materiais concretos e recursos digitais nas aulas de Matemática" e "a relevância da sistematização do registro e da formalização do conhecimento matemático como garantia da aprendizagem". Isso foi evidenciado ao longo do trabalho: os materiais concretos são importantes, mas apenas nos primeiros anos da escolarização, pois o desejo das professoras é que os alunos possam abandoná-los ao longo do percurso.

Ao fim e ao cabo, pode-se inferir que as entrevistadas consideram que a aprendizagem acontece quando os alunos abstraem, são capazes de resolver o conjunto de técnicas próprio da disciplina sem o apoio do material, seja ele concreto ou digital, e que esta aprendizagem está intimamente ligada ao processo de sistematizar seu pensamento a partir do registro escrito. Dessa forma, suas ações e escolhas pedagógicas respondem a regras de discursos piagetianos e platônicos, constituindo, assim, uma forma de ser professor de Matemática nos Anos Iniciais.

Inspiradas nos estudos de Foucault, finalizamos esta análise afirmando que não só o discurso é produzido como produz os sujeitos que dele fazem parte. Dessa forma, a docência seria também um efeito do discurso: "Se nós acreditamos que, quando se fala de algo, também se inventa, institui-se esse algo, é porque aquilo só pode ser pensado em estreita dependência e correlação com o que pode ser 'dito"” (BELLO, 2010, p. 550). A análise realizada mostrou algumas conexões entre o que as professoras falam e praticam em suas salas de aula.

\section{Considerações finais}

Nesta seção, temos o propósito de apresentar algumas implicações do estudo para a área da Educação Matemática, em especial, aquela produzida nos Anos Iniciais do Ensino Fundamental. Com o intuito de problematizar enunciados que conformam o discurso da 
Educação Matemática e seus efeitos de verdade sobre as práticas pedagógicas das professoras que atuam nos Anos Iniciais do Ensino Fundamental, o artigo mostrou que as docências das educadoras entrevistadas estão fortemente marcadas pela presença do uso do material concreto, por vezes ganhando contornos de recursos digitais, e pela importância da escrita e da sistematização dos saberes matemáticos por meio do treino, da repetição e do registro.

O uso dos materiais concretos é visto pelas entrevistadas como um facilitador da aprendizagem da Matemática escolar, ao lado do uso dos recursos digitais. No artigo, mostramos que essas concepções emergem de uma confluência entre as teorizações piagetianas, o pensamento de Rousseau e os documentos que regulam as práticas pedagógicas contemporâneas, como a Base Nacional Comum Curricular (2018).

Isso nos leva a concluir que a presença de materiais concretos nas aulas de Matemática é ainda uma verdade inquestionável, mas que novos artefatos agora ajudam a conformam esse conjunto de materiais: os recursos tecnológicos (principalmente os computadores com suas ferramentas e softwares) também passam a ser posicionados como "facilitadores" ou apoio para o ensino de Matemática na escola. Poderíamos aqui questionar: quais os sentidos do uso de recursos tecnológicos nas aulas de Matemática? Simplesmente atuar como apoio para o ensino de Matemática ou produzir novos conhecimentos e outras racionalidades mobilizadas pelos artefatos tecnológicos?

Uma segunda implicação desse estudo refere-se ao formalismo e uso do registro nas aulas de Matemática. Palavras como sistematizar, treinar, formalizar, abstrair estão presentes nas falas das entrevistadas, tomando essas ações como algo inquestionável e necessário: só aprende Matemática quem escreve. Essa ideia materializa-se nas práticas colocadas em funcionamento pelas professoras, mas o interessante é que a assepsia, uma das características que fazem parte do conjunto de regras do formalismo, ganha novos contornos no contexto pesquisado, esmaecendo a verdade de que aprender Matemática significa responder a uma determinada situação de uma única forma.

Os resultados encontrados nesta pesquisa posicionam as ações das professoras entrevistadas na intersecção de dois grandes campos teóricos que conformam o discurso da Educação Matemática: o construtivista e o platônico. Por um lado, estes campos vêm constituindo professoras que se utilizam do material concreto, seja ele físico ou digital, como forma de se chegar a um modelo esperado. Por outro lado, dentre os ideais platônicos, temos aqueles que consideram que todos chegam a um mesmo resultado, já que os objetos matemáticos são a-históricos e universais. Essa ideia materializa-se nas falas das docentes quando dizem que mesmo não seguindo o modelo proposto e não registrando da mesma 
forma, o aluno chega lá. Esse lá foi significado, por elas, como o ponto final do processo pedagógico: a abstração.

Percebe-se também que as práticas do campo da Pedagogia estão se produzindo e se reatualizando constantemente, não no sentido de inventar coisas novas, mas no sentido de (re)ver, (re)viver e, até mesmo, (re)inventar saberes sobre as melhores formas de se ensinar Matemática para crianças entre oito e dez anos de idade. Assim, pode-se configurar a sala de aula, numa perspectiva foucaultiana, como uma tecnologia que se utiliza da produção de saberes para estabelecer verdades, as quais passam a ser tomadas como inquestionáveis.

O estudo que realizamos buscou perceber algumas dessas verdades que circulam nos Anos Iniciais, que encontram terreno para irromper nas escolas e se configuram como inquestionáveis no campo da Educação. Inspiradas em Giorgio Agamben, ao analisar falas de professoras que estão em sala de aula, ministrando aulas de Matemática, nos colocamos em uma busca constante pelo não vivido. "É como se aquela invisível luz, que é o escuro do presente, projetasse sua sombra sobre o passado, e este, tocado por esse facho de sombra, adquirisse a capacidade de responder às trevas do agora" (AGAMBEN, 2009, p. 72). A partir do conhecimento do escuro do seu tempo, é possível voltar-se para o passado a fim de questioná-lo e entender suas consequências. Dessa forma, faz sentido pensar em olhar fixamente para as nossas "escolhas" pedagógicas, por exemplo, a fim de entendê-las e colocálas em suspeita. Os movimentos de entender e colocar em suspeita nos mobilizaram a escrever este artigo.

\section{Referências}

AGAMBEN, G. O que é o contemporâneo? E outros ensaios. Chapecó: Argos, 2009.

ANDRÉ, M. O que é um estudo de caso qualitativo em educação? Revista da FAEEBA - Educação e Contemporaneidade, Salvador, v. 22, n. 40, p.95-103, jul./dez. 2013.

AURICH, G.; BELLO, S. E. O dado na docência em Matemática e Foucault: uma constituição docente entre penduricalhos e ética. Em teia - Revista de Educação Matemática e Tecnológica Iberoamericana, Recife, v. 9, n. 2, p.1-23, ago./out. 2018.

BELLO, S. E. Jogos de Linguagem, práticas discursivas e produção de verdade: contribuições para a Educação (Matemática) contemporânea. Zetetike, Campinas, v. 18, p. 545-588, 2010.

BRASIL. Ministério da Educação. Diretrizes Curriculares Nacionais para a Educação Básica. Brasília: MEC, 2013.

BRASIL, Ministério da Educação. Base Nacional Comum Curricular - BNCC. Brasília: MEC, 2018. Disponível em: http://basenacionalcomum.mec.gov.br/a-base. Acesso em: nov. 2018. DAMAZIO JUNIOR, V.; VENSON, D. L. Reflexões sobre Matemática e Verdade. Bolema, Rio Claro, v. 33, n. 63, p. 434-448, abr. 2019. . 
FOUCAULT, M. A ordem do discurso. São Paulo: Loyola, 1996.

FOUCAUlT, M. Ditos e escritos V - Ética, Sexualidade, Política. Rio de Janeiro: Forense Universitária, 2004.

FOUCAULT, M. Arqueologia do saber. Rio de Janeiro: Forense Universitária, 2007.

GIONGO, I. M. Educação Matemática e disciplinamento de corpos e saberes: um estudo sobre a Escola Estadual Técnica Agrícola Guaporé. 2008. Tese (Doutorado em Educação) - Centro de Ciências Humanas, Universidade do Vale do Rio dos Sinos, São Leopoldo, 2008.

KNIJNIK, G. A ordem do discurso da matemática escolar e jogos de linguagem de outras formas de vida. Perspectivas da Educação Matemática, Campo Grande, v. 10, n. 22, p. 46-64, 2017.

KNIJNIK, G. Differentially positioned language games: ethnomathematics from a philosophical perspective. Educational Studies in Mathematics, New York, v. 80, p. 87-100, 2012.

KNIJNIK, G. et al. Etnomatemática em Movimento. Belo Horizonte: Autêntica Editora, 2012.

KNIJNIK, G.; DUARTE, C. G. Entrelaçamentos e dispersões de enunciados no discurso da Educação Matemática Escolar: um estudo sobre a importância de trazer a realidade dos alunos para as aulas de matemática. Bolema, Rio Claro, v. 23, n. 37, p. 863-886, 2010.

KNIJNIK, G.; WANDERER, F. Mathematics Education in Brazilian Rural Areas: An analysis of the Escola Ativa public policy and the Landless Movement Pedagogy. Open Review of Educational Research, London, v. 2, p. 143-154, 2015.

KNIJNIK, G.; WANDERER, F. Da importância do uso de materiais concretos nas aulas de matemática: um estudo sobre os regimes de verdade sobre a educação matemática camponesa. In: ENCONTRO NACIONAL DE EDUCAÇÃO MATEMÁTICA - ENEM, 9., 2007, Belo Horizonte. Anais ... Belo Horizonte: SBEM, 2007. p. 1-17.

MILANO, T. B. et al. Educação Matemática e Tecnologia: uma análise de discursos presentes no BOLEMA. Revista Eletrônica da Matemática, Caxias do Sul, v. 2, n. 2, p. 92-104, 2016.

MONTEIRO, A.; POMPEU JR, G. A Matemática e os Temas Transversais. São Paulo: Moderna, 2001.

PAZ, M. L.; FRADE, C. A História de Nair: a força da identidade institucional para a permanência na docência em Matemática. Bolema, Rio Claro, v. 30, n. 56, p. 1260-1279, dez. 2016.

QUARTIERI, M. T. A modelagem matemática na escola básica: a mobilização do interesse do aluno e o privilegiamento da matemática escolar. 2012. Tese (Doutorado em Educação) - Centro de Ciências Humanas, Universidade do Vale do Rio dos Sinos, São Leopoldo, 2012.

ROUSSEAU, J-J. Emílio; ou, Da educação. Rio de Janeiro: Bertrand Brasil, 2004.

SANTA, F. D. A criança e o seu mundo: considerações acerca da educação natural nos dois primeiros livros do Emílio de Rousseau. Educação, Santa Maria, v. 45, jan./dez. 2020.

SANTOS, J. W. Relações saber-poder: discursos, tensões e estratégias que (re)orientam a constituição do livro didático de Matemática. 2019. Tese (Doutorado em Educação) - Faculdade de Educação, Universidade Federal do Mato Grosso do Sul, Campo Grande, 2019. 
SANTOS, S. A. Experiências narradas no ciberespaço: um olhar para as formas de se pensar e ser professora que ensina matemática. 2009. Dissertação (Mestrado em Educação) - Faculdade de Educação, Universidade Federal do Rio Grande do Sul, Porto Alegre, 2009.

SILVEIRA, R. M. H. A entrevista na pesquisa em educação: uma arena de significados. In: COSTA, M. V. (org.). Caminhos investigativos II: outros modos de pensar e fazer pesquisa em educação. Rio de Janeiro: Lamparina, 2007. p. 117-138.

SOMMER, L. H. A ordem do discurso escolar. Rev. Bras. Educ., Rio de Janeiro, v. 12, n. 34, p. 57 67, 2007.

VALERO, P. Mathematics for All and the Promise of a Bright Future. In: HASER, B. U.; MARIOTTI, M. A. (ed.). Proceedings of the Eight Congress of the European Society for Research in Mathematics Education Middle East Technical University. Ankara: European Society for Research in Mathematics Education, 2013.

VEIGA-NETO, A. Foucault e a Educação. Belo Horizonte: Autêntica, 2007.

WALKERDINE, V. O raciocínio em tempos pós-modernos. Educação e Realidade, Porto Alegre, v. 20, n. 2, p. 207-226, 1995.

WANDERER, F.; CARNEIRO, F. H. F. Educação matemática em uma escola bilíngue para surdos.

Caderno Pedagógico, Lajeado, v. 13, n.1, p. 95-106, 2016.

Submetido em 19 de Julho de 2019. Aprovado em 22 de Abril de 2020. 